\title{
Hygroscopic Growth and Deliquescence of NaCl Nanoparticles Coated with Surfactant AOT $^{\dagger}$
}

\author{
Ahmad Alshawa, ${ }^{\ddagger,}$ Otto Dopfer," Christopher W. Harmon, ${ }^{\ddagger}$, Sergey A. Nizkorodov, ${ }^{*, \S}$ and \\ Joelle S. Underwood ${ }^{\S, \perp}$ \\ Department of Chemistry, University of California, Irvine, California 92697-2025, and Institut fuer Optik und \\ Atomare Physik, Technische Universitaet Berlin, Hardenbergstrasse 36, D-10623 Berlin, Germany
}

Received: November 09, 2008; Revised Manuscript Received: February 13, 2009

\begin{abstract}
Aerosolized nanoparticles of $\mathrm{NaCl}$ coated with variable amounts of surfactant AOT were generated by electrospraying $\mathrm{AOT} / \mathrm{NaCl}$ aqueous solutions, followed by neutralizing and drying the resulting particles. A tandem differential mobility analyzer was used to select a narrow size distribution of particles with mobility equivalent diameters below $20 \mathrm{~nm}$ and monitor their hygroscopic growth as a function of relative humidity. Effects of the particle size and relative amount of surfactant on the hygroscopic growth of $\mathrm{NaCl}$ were studied. For pure $\mathrm{NaCl}$ nanoparticles, the deliquescence relative humidity (DRH) increased as the particle size was decreased, in full agreement with previous measurements. Below the DRH the $\mathrm{NaCl}$ nanoparticles had an equivalent of one-four monolayers of water adsorbed on the surface. The addition of a sub-monolayer AOT coating reduced the DRH and suppressed the hygroscopic growth of the $\mathrm{NaCl}$ core. At AOT coverage levels exceeding one monolayer, a clear deliquescence transition was no longer discernible. The Zdanovskii-StokesRobinson (ZSR) model failed to predict the observed growth factors of mixed $\mathrm{AOT} / \mathrm{NaCl}$ nanoparticles reflecting a large contribution of the interfacial interactions between $\mathrm{NaCl}$ and $\mathrm{AOT}$ to the total free energy of the particles. There were indications that $\mathrm{AOT} / \mathrm{NaCl}$ nanoparticles prepared by the electrospray aerosol source were enhanced in the relative mass fraction of AOT in comparison with the solution from which they were electrosprayed.
\end{abstract}

\section{Introduction}

Atmospheric nanoparticles, also known as ultrafine particles, ${ }^{1}$ are typically defined as particles with aerodynamic diameters below $100 \mathrm{~nm}$. The physical basis for this size threshold is the unique ability of such particles to translocate through biological tissues. ${ }^{2,3}$ Atmospheric nanoparticles are directly emitted by a number of sources, such as diesel engines, ${ }^{4}$ and can also be produced by condensation of molecular precursors during particle nucleation events. ${ }^{5}$ Once formed, they undergo deposition onto larger particles and other available surfaces on time scales ranging from several seconds to several hours. ${ }^{6}$ Despite their relatively short atmospheric lifetimes, nanoparticles dominate the number concentration and make a significant contribution to the available surface area of particulate matter. ${ }^{1,7}$ The high surface-to-volume ratio of nanoparticles strongly favors atmospheric chemistry that is specific to the particle surfaces. ${ }^{8,9}$

Atmospheric particles can significantly expand in size by taking up water as the relative humidity $(\mathrm{RH})$ increases. This hygroscopic growth increases the particle's single scattering albedo and plays an important role in cloud droplet formation. ${ }^{10,11}$ Hygroscopicity of individual particles is normally quantified in terms of the growth factor (GF), the ratio of the measured particle mobility diameter $\left(d_{\mathrm{m}}\right)$ at a certain $\mathrm{RH}$ to that of the dry particle. ${ }^{12}$

\footnotetext{
† Part of the "Robert Benny Gerber Festschrift".

* Corresponding author, nizkorod@uci.edu.

* Graduate students who made equal contributions to this project.

$\S$ University of California, Irvine.

"Technische Universitaet Berlin.

${ }^{\perp}$ Current address: Department of Chemistry, Loyola University, New Orleans, LA 70118.
}

$$
\mathrm{GF}_{\text {mobility }}=\frac{d_{\mathrm{m}}^{\mathrm{wet}}}{d_{\mathrm{m}}^{\mathrm{dry}}}
$$

The extent and rate of the hygroscopic growth is a sensitive function of both the particle's initial diameter and the chemical composition. For highly soluble inorganic particles, such as $\mathrm{NaCl}$, and certain highly soluble organic particles, such as malonic acid, GF may experience a discontinuity at a welldefined deliquescence relative humidity (DRH) corresponding to a phase transition from a solid to a dissolved state. ${ }^{11,13-16}$ The reverse phase transition occurs at the efflorescence relative humidity (ERH), which can be considerably lower than DRH because of kinetic constraints. For example, $\mathrm{NaCl}$ particles experience almost no growth below its DRH of $75 \% .{ }^{17}$ At the DRH point, $\mathrm{NaCl}$ particles undergo a transition from its crystalline form into an aqueous droplet, which is accompanied by a prompt increase in the particle mobility diameter. The ERH for $\mathrm{NaCl}$ occurs at $\sim 45 \%$. $^{18}$

This study focuses on hygroscopic properties of nanoparticles with sizes below $\sim 20 \mathrm{~nm}$, which are interesting for a number of fundamentally important reasons. ${ }^{19}$ In this size range, there is a nontrivial contribution of the surface energy to the free energy of the particle:

$$
\begin{aligned}
G_{\text {particle }}= & \mu_{\text {bulk }} n_{\text {bulk }}+\mu_{\text {surface }} n_{\text {surface }} \approx \\
& \mu_{\text {bulk }} n_{\text {bulk }}+\sigma_{\text {surface }} A_{\text {particle }}
\end{aligned}
$$

$G, \mu, n, \sigma$, and $A$ stand for free energy, chemical potential, molar amount, surface tension, and particle surface area, respectively. 
In other words, the surface energy term in the free energy expression, which can be safely neglected for particles larger than $100 \mathrm{~nm}$, starts to be comparable in magnitude to the bulk free energy contribution..$^{20-24}$ As a result of the large surfaceto-volume ratios of nanoparticles, their GF, ERH, and DRH values can be size-dependent.

Only a few experimental and theoretical studies of hygroscopic growth of nanoparticles are currently available. Hämeri et al. ${ }^{25-27}$ were the first to measure GF for $8-60 \mathrm{~nm} \mathrm{NaCl}$ and $\left(\mathrm{NH}_{4}\right)_{2} \mathrm{SO}_{4}$ particles. They found that GF increases with increasing particle size and that the $\mathrm{DRH}$ for $\mathrm{NaCl}$ particles in this size range is higher than DRH for larger particles. ${ }^{17}$ They also observed "nonprompt" (gradual) deliquescence, a concept first described in a theoretical study of deliquescence of small particles by Mirabel. ${ }^{20}$ A modeling study by Russell and Ming ${ }^{22}$ expanded on Mirabel's work and showed that the observed sign and magnitude of the DRH shift in small $\mathrm{NaCl}$ particles is consistent with deliquescence of $\mathrm{NaCl}$ nanocrystals precoated with a thin layer of water (as opposed to completely dry particles below DRH assumed in ref 20).

More recent measurements by Biskos et al. ${ }^{28-30}$ challenged the nonpromptness of the deliquescence and showed that it can be attributed to the experimental artifacts in the operation of the tandem differential mobility analyzer used for these measurements. Contrary to the previous theoretical predictions, ${ }^{20,22}$ they could only observe the nanosize effect on DRH for $\mathrm{NaCl}$ particles but not for $\left(\mathrm{NH}_{4}\right)_{2} \mathrm{SO}_{4}$ particles. Gao et al. ${ }^{18}$ modeled the efflorescence of $\mathrm{NaCl}$ nanoparticles by combining the Köhler equation with homogeneous nucleation theory and correctly predicted the increase in ERH values for smaller particle sizes observed in ref 29.

As the particle size approaches molecular dimensions, the macroscopic description of phase transitions should become less meaningful. However, even for the smallest $6 \mathrm{~nm}$ particles of $\mathrm{NaCl}$ and $\left(\mathrm{NH}_{4}\right)_{2} \mathrm{SO}_{4}$ studied in refs 25, 26, 29, and 30, the GF values observed above DRH could still be accurately predicted using thermodynamic parameters appropriate for bulk samples after accounting for the particle shape effects. ${ }^{28,30}$ The observed particle size dependence of the DRH could also be modeled using standard thermodynamics approaches without having to resort to a molecular level description of the phase transitions. ${ }^{22}$ It was possible to use a macroscopic description for the theoretical prediction of phase transitions in even smaller particles (down to $2 \mathrm{~nm}$ in size) by allowing for phenomenological size dependence of the surface tension. ${ }^{23,31}$

Atmospheric particles generally represent complicated mixtures of organic and inorganic species with very different levels of water solubility. To better understand the consequences of having poorly miscible species in the same particle, hygroscopic properties of particles with inorganic core-organic shell morphologies were investigated by several groups. ${ }^{12,32-34}$ The organic material did not appear to inhibit the growth of the soluble inorganic core, even for cases when the organic material was the dominant constituent of particles. ${ }^{12,32}$ Measured GF values for the mixed particles were approximately consistent with the assumption that the organic and inorganic species adsorb water independently, in accordance with the ZdanovskiiStokes-Robinson (ZSR) model. ${ }^{33,34}$ Similar conclusions were reached in studies of water activities above the bulk mixtures of the same compounds. ${ }^{35,36}$ The main objective of this work is to test the effect of sparingly soluble organic coatings on hygroscopic properties of $\mathrm{NaCl}$ nanoparticles. To ensure that the organic layer is confined to the surface, we chose AOT, sodium bis(2-ethylhexyl) sulfosuccinate (Figure 1), a well-

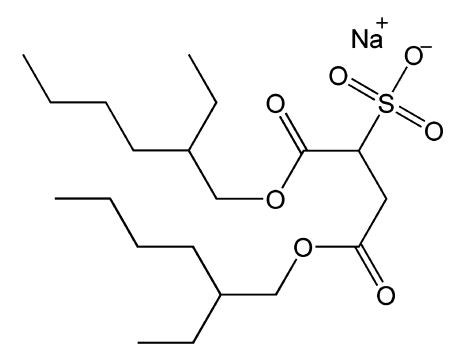

Figure 1. Sodium bis(2-ethylhexyl) sulfosuccinate (AOT): $\mathrm{C}_{20} \mathrm{H}_{37} \mathrm{NaO}_{7} \mathrm{~S}$, CAS 577-11-7, MW $444.56 \mathrm{~g} / \mathrm{mol}$.

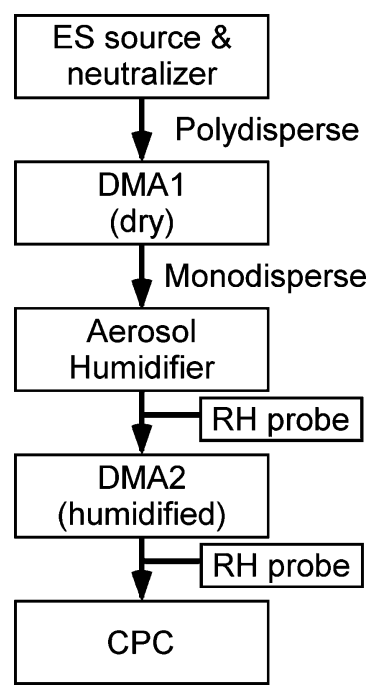

Figure 2. Experimental approach for generating, size selecting, conditioning, and monitoring hygroscopic growth of nanoparticles. Key: $\mathrm{RH}$, relative humidity; DMA, differential mobility analyzer; CPC, condensation particle counter; ES, electrospray.

known surfactant with a strong propensity for forming inverted micelles in condensed phase. ${ }^{37-39}$

\section{Experimental Methods}

Figure 2 shows an experimental schematic for generating nanoparticles and monitoring their hygroscopic growth. Nanoparticles containing $\mathrm{NaCl}$ and AOT were generated with a homebuilt electrospray aerosol source. Variable amounts of $\mathrm{NaCl}$ (Sigma-Aldrich, 99.999\%) and AOT (Fluka, $\geq 99.0 \%$ ) were dissolved in deionized HPLC grade water (OmniSolv, $<8$ $\mu \Omega \cdot \mathrm{cm})$ to achieve a combined concentration of $\sim 1 \mathrm{~g} / \mathrm{L}$. A small amount $(<5 \%)$ of methanol (Sigma-Aldrich, HPLC grade, $>99.9 \%$ ) was added to the solution in order to enhance the electrospray cone stability. The solution was pushed through a $5 \mathrm{~cm}$ long, $100 \mu \mathrm{m}$ i.d. quartz capillary with a syringe pump (780100 KD Scientific) at a typical flow rate of $\sim 1 \mu \mathrm{L} / \mathrm{min}$. High voltage $(2-3 \mathrm{kV})$ was applied directly to the stainless steel needle of the syringe (Hamilton GT, $500 \mu \mathrm{L}$ ). The capillary entered a small $\left(\sim 5 \mathrm{~cm}^{3}\right)$ chamber equipped with transparent windows for easy viewing of the electrospray jet with a microscope objective and CCD camera. The end of the capillary was positioned $3-5 \mathrm{~mm}$ away from the electrically grounded $6 \mathrm{~mm}$ o.d. entrance tube of a bipolar neutralizer $\left({ }^{85} \mathrm{Kr}, 10 \mathrm{mCi}\right.$, TSI model 3054). A $\sim 1$ SLM (standard liter per minute) flow of dry air was sent into the chamber to help with carrying the aerosol into the neutralizer.

The electrospray source produced particle concentrations in excess of $10^{6}$ particles per $\mathrm{cm}^{3}$ in a relatively narrow distribution of particle sizes characterized by geometric standard deviations 
(GSD) of $\sim 1.2$. The particles were free of the residual solvents (see discussion below). Mean particle diameter could be varied from 5 to $30 \mathrm{~nm}$ by adjusting the solution concentration and solution flow rate. For each size, the electrospray voltage had to be adjusted for optimal stability. For this size range, more than $90 \%$ of the particles are expected to be uncharged after the neutralization step, which establishes a near-Boltzmann distribution of charges on the particles. ${ }^{40}$ The rest of the particles should be singly charged, with a negligible contribution $(<1 \%)$ from multiply charged particles. ${ }^{41}$ For comparison purposes, pure $\mathrm{NaCl}$ particles were also generated by vaporization and condensation of solid $\mathrm{NaCl}$ as described by Fuks. ${ }^{42}$ This method produced higher concentrations of particles $\left(\sim 10^{7} \mathrm{~cm}^{-3}\right)$ than the electrospray source but it could not be used for making AOT/ $\mathrm{NaCl}$ mixed particles.

A $0.30-0.40$ SLM flow coming from the electrospray source was directed into the first differential mobility analyzer (DMA1, TSI 3085). The applied dc voltage in DMA1 was fixed to allow a narrower distribution (GSD $\sim 1.05$ ) of particle mobility diameters to pass through (at the expense of losing $~ 99 \%$ of the uncharged particles). The DMA1 sheath flow (3.0-4.0 SLM) was operated with a closed loop configuration in which the excess air was filtered twice, dried with a Nafion dryer (PermaPure, MD-110), and recirculated. The resulting RH of the sheath flow was approximately $1-3 \%$.

Size selected particles were brought to a desired RH by using a Nafion humidifier (Perma Pure, MD-110-48E-F) which consisted of a $2 \mathrm{~mm}$ wide, $120 \mathrm{~cm}$ long Nafion tube carrying the aerosol flow placed inside a $6 \mathrm{~mm}$ ID plastic tube carrying humidified air in the opposite direction. A rapid and stable adjustment of a desired RH inside the Nafion humidifier was achieved by mixing highly humidified air ( $\mathrm{RH}>95 \%)$ and dry air in different proportions. RH was monitored by Vaisala HMP237 probes, which were periodically calibrated against $\mathrm{RH}$ above standard saturated salt solutions. The best achievable accuracy and precision of the probes were $\pm 1.0 \% \mathrm{RH}$ and $\pm 0.1 \% \mathrm{RH}$, respectively, in the $0-90 \% \mathrm{RH}$ range.

Humidified particles were sized in the second nano-DMA (DMA2, TSI 3085) operated in a scanning mode, and counted by a condensation particle counter (CPC, TSI 3025A). The estimated residence time of particles in the humidified flow (Nafion tube $+\mathrm{RH}$ probe + DMA2) was $\sim 5 \mathrm{~s}$. The sheath air of DMA2 (3.0-4.0 SLM; 10:1 sheath:aerosol flow ratio) had a closed loop configuration with an independent control of $\mathrm{RH}$, which was adjusted by mixing humid ( $\mathrm{RH}>95 \%)$ and dry air in different proportions. The excess air was filtered twice and heat exchanged to match the sheath air temperature, which was typically $22{ }^{\circ} \mathrm{C}$. RH was monitored by a separate calibrated Vaisala HMP237 probe. As a matter of experimental convenience, the DMA2 sheath flow was maintained at a level that was slightly higher than that of the aerosol flow, typically by 0-3\% RH. When the difference between the DMA2 sheath flow and the aerosol flow RH was larger than zero, the final particle growth took place inside the DMA2 sheath air. All growth factors measured in this work are presented as a function of the sheath flow RH encountered by the particles in DMA2.

In most measurements, the RHs of the aerosol and DMA2 flows were slowly increased in parallel. The electrospray source was operated continuously, and the final particle size distributions were measured several times after the RH values stabilized at a desired level. Readings from all RH probes were continuously monitored by a computer. It took approximately 2 to 3 days to record each growth curve over a 5-90\% $\mathrm{RH}$ range. After a $12 \mathrm{~h}$ period it was usually necessary to stop the

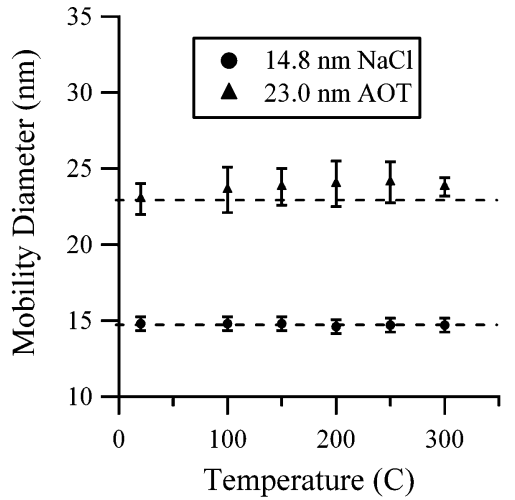

Figure 3. Mean particle sizes for pure $\mathrm{NaCl}$ and $\mathrm{AOT}$ aerosol as a function of temperature at the entrance of a diffusion drier. Error bars are $3 \sigma$ from repeated measurements.

electrospray source and clean the neutralizer from solid AOT/ $\mathrm{NaCl}$ deposits forming at its entrance tube. In order to achieve reproducibility in the measured GF and DRH values, it was critical to keep both DMAs and all aerosol tubing free of contamination by volatile organics, especially for measurements on pure $\mathrm{NaCl}$ particles.

\section{Results}

Characterization of Particles. To confirm that particles produced by the electrospray source were free of the residual solvent, the particle size distribution was measured before and after they passed through a diffusion drier with a resistively heated inlet. For this measurement, the initial particle size was not preselected with DMA1. Figure 3 shows the mean geometric size of pure $\mathrm{NaCl}$ and AOT particles as a function of the inlet temperature. As the temperature is increased from 25 to 300 ${ }^{\circ} \mathrm{C}$, no distinctive change in the mean size is observed for the $\mathrm{NaCl}$ and AOT particles within the experimental uncertainties in the measured mobility equivalent diameters ( $3 \sigma$ error bars are shown in Figure 3). The uncertainties are somewhat larger for AOT compared to $\mathrm{NaCl}$ because the former has a somewhat broader particle size distribution.

An SEM/TEM (scanning/transmission electron microscopy) grid was immersed in the aerosol flow directly after the neutralizer for several minutes. Collected particles composed of pure AOT were imaged with SEM and TEM. The images of isolated particles revealed that they were spherical, with the observed diameters being consistent with the mobility equivalent diameters measured by the DMA apparatus. A number of AOT particles appeared to conglomerate with each other on the grids, but the individual particles retained their initial shape within the conglomerates. The particles were stable under the vacuum conditions of the electron microscope chamber. These observations provided additional confirmation that the particles were essentially solvent-free.

We have attempted to quantify the relative AOT and $\mathrm{NaCl}$ mass fractions in the particles generated by the electrospray aerosol source by collecting the $\mathrm{AOT} / \mathrm{NaCl}$ particles and measuring the sulfur-to-chlorine ratio with X-ray photoelectron spectroscopy (XPS) methods. The results were not conclusive due to the small mass of collected material. In this paper, we assume that the relative $\mathrm{NaCl}$ and AOT mass fractions in the particles are approximately the same as in the original solution. However, we discuss possible deviations from this assumption at the end of this paper.

Hygroscopic Growth of Pure $\mathrm{NaCl}$ Nanoparticles. $\mathrm{NaCl}$ was selected as the inorganic core material for these experiments 
TABLE 1: Shape Corrections for the Measured Growth Factors of $\mathrm{NaCl}$ Particles

\begin{tabular}{cclc}
\hline$d_{\mathrm{m}}^{\text {dry }}(\mathrm{nm})$ & $K n$ & $\chi(K n)$ & $d_{\mathrm{ve}}(\mathrm{nm})$ \\
\hline 9.0 & 14.7 & $1.25^{a}$ & 8.1 \\
10.8 & 12.2 & $1.25^{a}$ & 9.7 \\
10.9 & 12.1 & 1.25 & 9.8 \\
14.0 & 9.43 & $1.23^{b}$ & 12.5 \\
14.1 & 9.36 & 1.23 & 12.7 \\
17.0 & 7.76 & 1.23 & 15.2
\end{tabular}

${ }^{a}$ Calculated from Dahneke et al. ${ }^{68-70}{ }^{b}$ Calculated in this work by methods of DeCarlo et al. ${ }^{52}$

because of the wide availability of experimental and theoretical data on wetting of pure $\mathrm{NaCl}$ nanoparticles, ${ }^{18,20,22-30}$ larger $\mathrm{NaCl}$ particles, ${ }^{13,16,17,43-45}$ and $\mathrm{NaCl}$ surfaces (only a few selected references are cited here). ${ }^{46-51} \mathrm{~A}$ number of reference experiments on pure $\mathrm{NaCl}$ nanoparticles were conducted in order to validate the operation of the tandem nano-DMA apparatus.

Dry $\mathrm{NaCl}$ particles have a cubic shape, ${ }^{45}$ whereas the deliquesced $\mathrm{NaCl}$ particles are spherical. In order to accurately quantify the degree of the particle hygroscopic growth, the observed GF values must be corrected for this change in shape. ${ }^{28}$ The measured mobility diameters of dry $\mathrm{NaCl}$ particles $\left(d_{\mathrm{m}}\right)$ were converted into diameters of volume-equivalent spheres $\left(d_{\mathrm{ve}}\right)$ using eq 3, where $\chi_{\mathrm{t}, \mathrm{v}}$ is the geometric shape factor (in the appropriate flow regime) and $C_{\mathrm{c}}(d)$ is the Cunningham slip correction factor. ${ }^{52}$

$$
\frac{d_{\mathrm{m}}}{C_{\mathrm{c}}\left(d_{\mathrm{m}}\right)}=\frac{d_{\mathrm{ve}} \chi_{\mathrm{t}, \mathrm{v}}}{C_{\mathrm{c}}\left(d_{\mathrm{ve}}\right)}
$$

The shape-corrected growth factors were then calculated as follows (note the difference between eqs 1 and 4)

$$
\mathrm{GF}_{\text {corrected }}=\frac{d_{\mathrm{ve}}^{\mathrm{wet}}}{d_{\mathrm{ve}}^{\mathrm{dry}}}
$$

For irregular particles, $d_{\mathrm{m}}$ is always larger than $d_{\mathrm{ve}}$ because they experience more drag compared to spherical particles of the same volume, and therefore $\chi_{\mathrm{t}, \mathrm{v}} \geq 1$. The Cunningham slip correction factor is a function of the Knudsen number $(K n)$. This factor accounts for the fact that particles do not experience as much drag in the free molecular flow regime $(K n>10)$ as they do in the continuum flow regime $(K n<0.1)$

$$
\begin{gathered}
C_{\mathrm{c}}(K n)=1+K n\left[\alpha+\beta \exp \left(-\frac{\gamma}{K n}\right)\right] \\
K n=\frac{2 \lambda}{d}
\end{gathered}
$$

The empirical parameters $\alpha, \beta$, and $\gamma$ are 1.142, 0.558 , and 0.999 , respectively. ${ }^{53}$ Parameter $\lambda$ is the mean free path in air at 1 atm $(\sim 65 \mathrm{~nm})$. For illustrative purposes, Table 1 lists calculated values of $K n, d_{\mathrm{ve}}$, and $\chi_{\mathrm{t}, \mathrm{v}}$ for several mobilityequivalent sizes of $\mathrm{NaCl}$ particles.

Figure 4 shows the shape-corrected growth curves for $\mathrm{NaCl}$ nanoparticles with mobility diameters of $9,11,14$, and $17 \mathrm{~nm}$. The dashed lines in Figure 4 indicate the predicted DRH values from the empirical power law determined by Biskos et al. ${ }^{29}$ The observed values of DRH are in good agreement with the previous measurements; the deviations are within the accuracy of the $\mathrm{RH}$ probes. We were also able to confirm the discrete nature of deliquescence of $\mathrm{NaCl}$ nanoparticles (reported in Figure 2 of ref 29), wherein a bimodal particle size distribution is observed in the immediate vicinity of the deliquescence transition.

Present measurements also confirm that postdeliquescence GF (that is, GF measured above the DRH point) decreases with decreasing dry diameter as a consequence of the Kelvin effect. ${ }^{30}$ Table 2 shows the mobility GF (not corrected for the shape effects) for $\mathrm{NaCl}$ nanoparticles at $80 \% \mathrm{RH}$, when particles are already deliquesced. Within the experimental uncertainties, the GF values measured in this work for 9, 11, 14, and $17 \mathrm{~nm}$ particles, and in ref 28 for $6,8,10,15,20,30,40$, and $60 \mathrm{~nm}$ particles increase monotonically with the particle mobility diameter. In summary, our tandem nano-DMA instrument correctly reproduces the shapes of the growth curves and the $\mathrm{GF}$ values for $\mathrm{NaCl}$ nanoparticles.

Hygroscopic Growth of AOT/NaCl Nanoparticles. Figure 5 shows the measured hygroscopic growth curves for $17 \mathrm{~nm}$ particles containing variable amounts of AOT and $\mathrm{NaCl}$. Shapecorrected GFs for pure $\mathrm{NaCl}$ particles are included for reference. No shape correction is applied to the measured GF for mixed $\mathrm{AOT} / \mathrm{NaCl}$ nanoparticles because they are assumed to be spherical. The particles are assumed to have the same relative weight fraction of $\mathrm{AOT}$ and $\mathrm{NaCl}$ as in the aqueous solution that is electrosprayed (the validity of this assumption will be discussed below). The 5 wt $\%$ AOT/ $\mathrm{NaCl}$ (this notation means $5 \%$ AOT and $95 \% \mathrm{NaCl}$ by weight) nanoparticles have a growth curve that is qualitatively similar to that of pure $\mathrm{NaCl}$; however the DRH is reproducibly lower by approximately $3 \% \mathrm{RH}$ and the postdeliquescence growth is suppressed. As the concentration of AOT increases, the apparent location of the deliquescence transition shifts to lower RH values and the GF values decrease in magnitude. The deliquescence of 5 and $25 \mathrm{wt} \% \mathrm{AOT} / \mathrm{NaCl}$ nanoparticles can be characterized as "prompt"; i.e., the transition happens over a relatively narrow range of RH. However, the 50 and 75 wt \% AOT/NaCl nanoparticles deliquesce over $\sim 5 \%$ RH units. The 75 wt \% AOT/ $\mathrm{NaCl}$ nanoparticles show lower $\mathrm{GF}$ than $50 \mathrm{wt} \% \mathrm{AOT} / \mathrm{NaCl}$ nanoparticles at lower $\mathrm{RH}$ values $(65-75 \% \mathrm{RH})$ and then converge to the same growth curve at higher values $(75-86 \%)$. Pure AOT particles display negligible growth over this $\mathrm{RH}$ range.

Figure 6 shows measured hygroscopic growth curves for 9 nm AOT/NaCl particles (0 wt \% AOT, 25 wt \% AOT, and 100 wt \% AOT). The growth curves of 9 and $17 \mathrm{~nm} 25 \mathrm{wt} \%$ AOT/ $\mathrm{NaCl}$ particles are quite different. The most striking difference is the lack of discernible deliquescence transition in the $9 \mathrm{~nm}$ particles. A gradual uptake of water over the course of nearly $30 \% \mathrm{RH}$ units is observed instead. The final growth factors are considerably suppressed in $9 \mathrm{~nm}$ particles as opposed to the 17 nm particles.

Measurements for Bulk Mixtures. To investigate bulk effects that added surfactants may have on hygroscopic interactions of $\mathrm{NaCl}$ and water, experiments were conducted in which $\mathrm{RH}$ was measured above saturated solutions of $\mathrm{NaCl}, \mathrm{NaNO}_{3} /$ $\mathrm{NaCl}$, and AOT/NaCl. In all cases, a mixture of $20 \mathrm{~g}$ of solid and $10 \mathrm{~mL}$ of $\mathrm{H}_{2} \mathrm{O}$ was mixed in a $280 \mathrm{~cm}^{3}$ sealed chamber. $\mathrm{RH}$ in the chamber was measured after it stabilized, typically some $24 \mathrm{~h}$ after the mixture was prepared. The results are summarized in Table 3. Mixing $\mathrm{NaCl}$ and $\mathrm{NaNO}_{3}$ reduced the equilibrium $\mathrm{RH}$, as expected. ${ }^{15}$ On the contrary, the addition of 

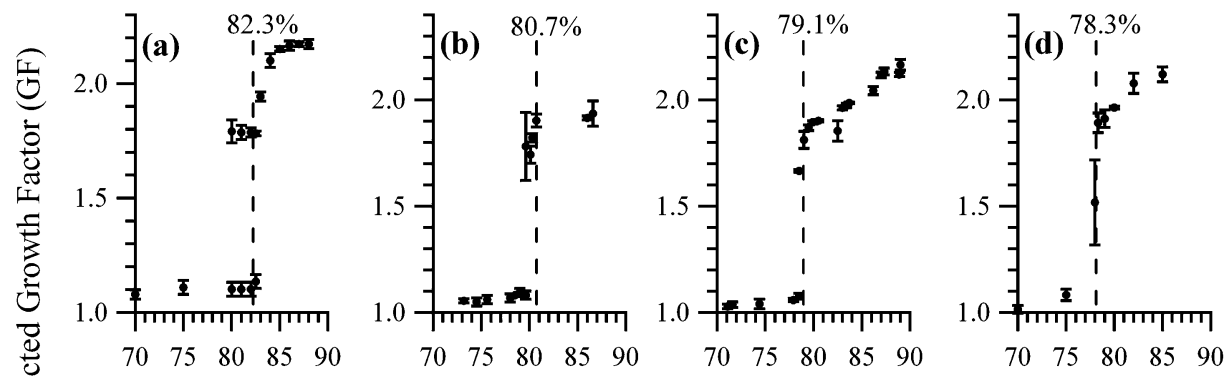

Figure 4. Shape-corrected growth curves ( $2 \sigma$ errors) of pure $\mathrm{NaCl}$ nanoparticles: $d_{\mathrm{m}}=$ (a) $9 \mathrm{~nm}$; (b) $11 \mathrm{~nm}$; (c) $14 \mathrm{~nm}$; (d) $17 \mathrm{~nm}$. Special attention is given to the region before deliquescence for $d_{\mathrm{m}}=9,11,14,17 \mathrm{~nm}$ particles in panels e, $\mathrm{f}, \mathrm{g}$, and $\mathrm{h}$, respectively. Water monolayer coverage was calculated from the GF values as described in the text. The dashed lines are calculated DRH from ref 28.

TABLE 2: Nanosize Effects on GF of NaCl Nanoparticles at $80 \%$ RH

\begin{tabular}{ccc}
\hline$d_{\mathrm{m}}(\mathrm{nm})$ & mobility $\mathrm{GF}^{a}$ & mobility $\mathrm{GF}^{b}$ \\
\hline 6 & & $1.45^{c}$ \\
8 & & $1.55^{c}$ \\
9 & $1.57 \pm 0.05$ & \\
10 & & $1.55^{c}$ \\
11 & $1.52 \pm 0.04$ & \\
14 & $1.66 \pm 0.01$ & \\
15 & & 1.68 \\
17 & $1.71 \pm 0.01$ & \\
20 & & 1.71 \\
30 & & 1.74 \\
40 & & 1.76 \\
60 & & 1.75 \\
$\infty$ & & 1.84
\end{tabular}

${ }^{a}$ This work; $2 \sigma$ error bars result from averaging repeated measurements. ${ }^{b}$ From Biskos et al. ${ }^{28}{ }^{c}$ Growth factor on the efflorescence branch in the vicinity of $80 \%$ RH. ${ }^{28}$

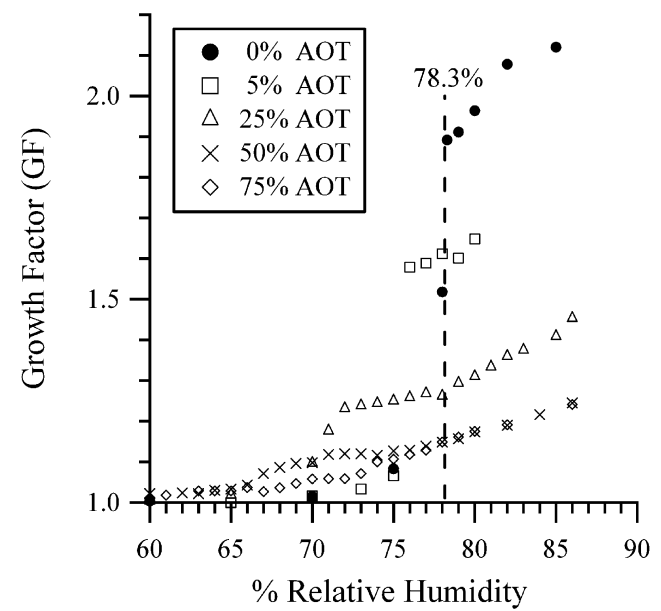

Figure 5. Measured growth curves for $17 \mathrm{~nm} \mathrm{AOT/NaCl}$ particles for different wt \% of AOT. The $\mathrm{NaCl}(0 \mathrm{wt} \%$ AOT) GF values are shape-corrected. The dashed line shows the expected DRH for $17 \mathrm{~nm}$ $\mathrm{NaCl}$ particles. Error bars are not shown to avoid congestion.

AOT to the saturated $\mathrm{NaCl}$ solutions had no effect on the equilibrium vapor pressure of water.

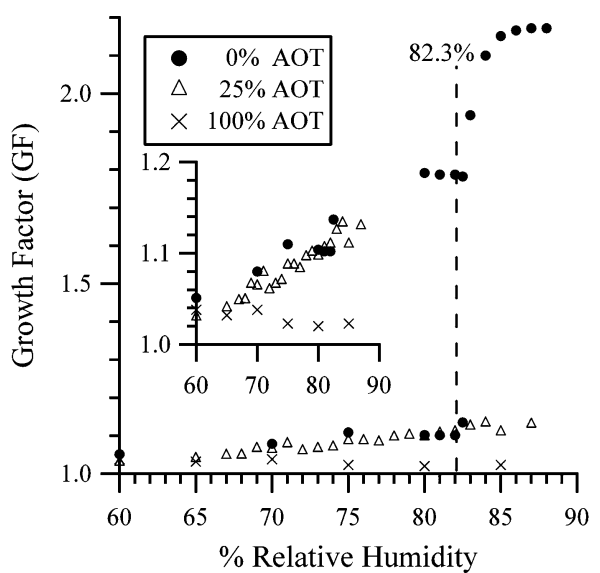

Figure 6. Measured growth curves for $9 \mathrm{~nm} \mathrm{AOT} / \mathrm{NaCl}$ particles for different wt $\%$ of AOT. Error bars are not shown to avoid congestion.

\section{Discussion}

Predeliquescence Wetting of $\mathrm{NaCl}$ Nanoparticles. The theoretical interpretation for the nanosize effect on deliquescence of pure $\mathrm{NaCl}$ nanoparticles has been provided by Russell and Ming. ${ }^{22}$ They considered a three-phase system consisting of water vapor, crystalline $\mathrm{NaCl}$, and a thin layer of adsorbed surface water. They showed that for realistic values of the surface tension at the $\mathrm{NaCl}$-air, $\mathrm{NaCl}$-surface water, and surface water-air interfaces, a thin layer of adsorbed surface water increases the free energy of the wetted particle. This must be compensated by the corresponding increase in the free energy of the deliquesced particle

$$
\Delta G^{\text {deliquescence }}=G_{\text {particle }}^{\text {deliquesced }}-G_{\text {particle }}^{\text {wetted }}=0
$$

which in turn increases the water activity above the particle surface at the deliquescence point. This effect of the surface tensions on the deliquescence equilibrium becomes negligibly small for particles that are larger than $100 \mathrm{~nm}$ in size.

The existence of adsorbed $\mathrm{H}_{2} \mathrm{O}$ on the surface of $\mathrm{NaCl}$ below DRH is consistent with experimental observations in this and other laboratories. For example, previous measurements on bulk 
TABLE 3: Water Activities above Saturated Solutions of AOT and $\mathrm{NaCl}^{a}$

\begin{tabular}{|c|c|c|}
\hline mixture & description & measured \% RH \\
\hline $\mathrm{NaCl}$ & $20 \mathrm{~g}$ of solid covered with $10 \mathrm{~mL}$ of $\mathrm{H}_{2} \mathrm{O}$ & 76.0 \\
\hline $\mathrm{NaNO}_{3}+\mathrm{NaCl}\left(\mathrm{X}_{\mathrm{NaCl}}=0.40 ;\right.$ eutonic mix $)$ & $20 \mathrm{~g}$ of solid covered with $10 \mathrm{~mL}$ of $\mathrm{H}_{2} \mathrm{O}$ & 69.0 \\
\hline $\mathrm{AOT}+\mathrm{NaCl}\left(\mathrm{X}_{\mathrm{NaCl}}=0.75\right)$ & $20 \mathrm{~g}$ of solid emulsified with $10 \mathrm{~mL}$ of $\mathrm{H}_{2} \mathrm{O}$ & 76.0 \\
\hline $\mathrm{AOT}+\mathrm{NaCl}$ & $20 \mathrm{~g}$ of solid $\mathrm{NaCl}$ covered with $10 \mathrm{~mL}$ of $0.5 \mathrm{~g} / \mathrm{L}$ AOT solution & 76.0 \\
\hline
\end{tabular}

$\mathrm{NaCl}$ showed that $\mathrm{NaCl}$ acquires 3-4 monolayers of water above $70 \% \mathrm{RH}^{46,48} \mathrm{~A}$ tandem nano-DMA experiment conducted on $8-15 \mathrm{~nm} \mathrm{NaCl}$ nanoparticles showed that the surfaces adsorb $0.5-2$ monolayers of water between 40 and $60 \%$ RH. ${ }^{27}$ Recent environmental TEM, ambient pressure XPS, and scanning force microscopy studies also revealed a layer of liquid-like water prior to deliquescence on $\mathrm{NaCl}$ surfaces. ${ }^{43-45,54}$ The addition of 2 monolayers of water onto a $10 \mathrm{~nm}$ particle translates into a GF of approximately 1.05 . This level of coverage with water is readily detectable in a tandem nano-DMA experiment (typical uncertainties in our GF measurements are on the order of $\pm 2 \sigma$ $= \pm 0.02)$. In contrast, the same level of coverage for a $1 \mu \mathrm{m}$ particle would correspond to GF of only 1.0005, which is not measurable with current mobility techniques.

Figure 4 shows the shape-corrected growth factors for $d_{\mathrm{m}}=$ 9, 11, 14, and $17 \mathrm{~nm} \mathrm{NaCl}$ particles, with special attention paid to the region immediately before the deliquescence point. GF values were converted into effective coverage of water $\left(\Theta_{w}\right)$ by using eq 8 .

$$
\Theta_{\mathrm{w}}=\frac{S_{\mathrm{w}}}{S_{\mathrm{NaCl}}}
$$

$S_{\mathrm{NaCl}}=6.4 \times 10^{14} \mathrm{~cm}^{-2}$ is the surface density of ion pairs for the $\mathrm{NaCl}(001)$ surface. ${ }^{55}$ Surface concentration of adsorbed water, $S_{\mathrm{w}}$, was calculated from $d_{\mathrm{ve}}$, which were calculated from the experimentally determined values of $d_{\mathrm{m}}$ as described above.

$$
S_{\mathrm{w}}=\frac{N_{\mathrm{w}}}{\pi\left(d_{\mathrm{ve}}^{\mathrm{dry}}\right)^{2}}=\frac{\rho_{\mathrm{w}}^{\mathrm{mol}} \Delta V_{\mathrm{ve}}}{\pi\left(d_{\mathrm{ve}}^{\mathrm{dry}}\right)^{2}}=\frac{1}{6} \rho_{\mathrm{w}}^{\mathrm{mol}} d_{\mathrm{ve}}^{\mathrm{dry}}\left(\mathrm{GF}^{3}-1\right)
$$

In eq $9, N_{\mathrm{w}}$ is the total number of adsorbed water molecules, $\rho_{\mathrm{w}}^{\mathrm{mol}}$ is the molecular density of adsorbed water (33 molecules $\mathrm{nm}^{-3}$ ), and $\Delta V_{\text {ve }}$ is the particle volume change due to the water adsorption.

The structure of water on a $\mathrm{NaCl}(001)$ surface was previously investigated by FTIR spectroscopy. ${ }^{46}$ Researchers concluded that for $\Theta_{w} \leq 0.5$, water molecules aggregate into islands or clusters on the surface held together by hydrogen bonds and electrostatic surface attraction; at $0.5 \leq \Theta_{\mathrm{w}} \leq 2.5$ a transition region occurs with islands and a multilayer thin film; at $2.5 \leq \Theta_{\mathrm{w}} \leq 3.5 \mathrm{a}$ multilayer film with properties similar to those of bulk liquid water exists; and finally, the range $\Theta_{w} \geq 3.5$ has been called the presolution region. Equating the water density to 33 molecules $\mathrm{nm}^{-3}\left(1.0 \mathrm{~g} \mathrm{~cm}^{-3}\right)$ is therefore appropriate only at sufficiently large coverage. At low coverage levels, the $\Theta_{\mathrm{w}}$ values calculated from eqs 8 and 9 and shown in Figure 4 are likely to be overestimated. As water adopts on an icelike structure at low coverage levels, a more appropriate density in the low coverage regime should be somewhere between 30 and 33 molecules $\mathrm{nm}^{-3}$. Despite the admittedly approximate treatment of the water uptake, the coverage levels predicted from eqs 8 and 9 support the notion that the $\mathrm{NaCl}$ crystal is coated with several monolayers of water below the deliquescence transition.

Hygroscopic Growth of $\mathbf{1 7} \mathbf{~ n m ~ A O T / N a C l}$ Particles. Before discussing the hygroscopic growth of $\mathrm{AOT} / \mathrm{NaCl}$ particles, we need to estimate the initial coverage of $\mathrm{NaCl}$ with AOT. This can only be done approximately because the details of structure, composition, and mobility of the $\mathrm{AOT} / \mathrm{NaCl}$ particles generated by the electrospray source are not known. The first approximation that we have to make is that the relative amounts of $\mathrm{NaCl}$ and AOT in the nanoparticles are the same as those in the starting solution. The second assumption is that the AOT/NaCl nanoparticles have a spherical shape. This assumption is not likely to hold at very low AOT coverage levels, when there is not enough surfactant to significantly perturb the $\mathrm{NaCl}$ surface. Furthermore, AOT is likely to segregate into islands on $\mathrm{NaCl}$ at sub-monolayer coverage levels; this is similar to the behavior of fatty acids on surfaces. ${ }^{56,57}$ However, with AOT coverage approaching a monolayer, it is reasonable to assume that the particles are uniformly coated with AOT and are close to spherical.

We also assume that AOT forms a film on the $\mathrm{NaCl}$ surface (as opposed to an internally mixed particle). This assumption is consistent with observations by Woods et al. ${ }^{58}$ who examined morphology of the 70-100 $\mathrm{nm} \mathrm{NaCl}$ particles containing $\sim 5$ wt \% SDS (sodium dodecyl sulfate; another well-known surfactant) using a probe-molecule spectroscopy technique. In their experiments, the structure of the 70-100 nm 5 wt \% SDS/ $\mathrm{NaCl}$ particles above DRH was inverted-micelle-like; i.e., SDS was distributed on the surface with its nonpolar tails sticking out. Below the DRH, the morphology was consistent with a thin oily film of SDS on a solid salt crystal.

Our final assumption is that the AOT surface film is not porous; in other words, a rigid core-shell model is applicable to AOT/NaCl particles at a monolayer coverage level. Tsai et al. ${ }^{59}$ showed that gold nanoparticles $(10-60 \mathrm{~nm})$ coated with self-assembled monolayers (SAMs) of alkanethiols appeared to have a "soft" organic coating. The SAM/Au particle size deduced from the mobility measurements was smaller than the size expected from purely geometric considerations. ${ }^{59} \mathrm{We}$ assume that the tapered shape of the AOT molecule will make the curved organic surface more compact, thus minimizing the effect of the organic coating on the physical diameter versus mobility diameter relationship.

With these approximations, the diameter of the $\mathrm{NaCl}$ core and the overall particle diameter can be related to each other in the following way

$$
d_{\mathrm{NaCl}}=\left(\frac{\mathrm{wt}_{\mathrm{NaCl}} \rho_{\mathrm{AOT}} d_{\mathrm{particle}}^{3}}{\rho_{\mathrm{NaCl}}-\left(\rho_{\mathrm{NaCl}}-\rho_{\mathrm{AOT}}\right) \mathrm{wt}_{\mathrm{NaCl}}}\right)^{1 / 3}
$$

$w t_{\mathrm{NaCl}}$ is the weight fraction of $\mathrm{NaCl}$ in the solution, $\rho_{\mathrm{NaCl}}$ is the density of the $\mathrm{NaCl}$ core, $\rho_{\text {AOT }}$ is the density of the AOT 
TABLE 4: Estimated Surface Coverage for 17 nm AOT/NaCl Particles

\begin{tabular}{|c|c|c|c|c|c|c|}
\hline wt $\% \mathrm{AOT}_{\text {sol }}$ & $d_{\mathrm{NaCl}}(\mathrm{nm})^{a}$ & anticipated $\Theta_{\mathrm{AOT}}^{b}$ & $\mathrm{GF}_{\mathrm{NaCl}(\text { core) })}(80 \% \mathrm{RH})^{c}$ & $\mathrm{GF}_{\text {particle }}(80 \% \mathrm{RH})$ & apparent wt $\% \mathrm{AOT}^{d}$ & apparent $\Theta_{\mathrm{AOT}}{ }^{e}$ \\
\hline 5.0 & 16.5 & 0.1 & 1.70 & 1.65 & 4.9 & 0.05 \\
\hline 25 & 14.4 & 0.4 & 1.64 & 1.31 & 40 & 0.6 \\
\hline 50 & 11.8 & 0.9 & 1.62 & 1.17 & 62 & 1.3 \\
\hline
\end{tabular}

${ }^{a}$ Calculated from eq 10. ${ }^{b}$ Calculated from eqs 11 and 12. ${ }^{c}$ Estimated from data in Table 2. ${ }^{d}$ Calculated from eq $14 .{ }^{e}$ Calculated from apparent wt \% AOT and eq 10 iteratively, third iteration is reported.

outer layer, and $d$ stands for diameter. While it is reasonable to assume the bulk density for the $\mathrm{NaCl}$ core $\left(2.165 \mathrm{~g} \mathrm{~cm}^{-3}\right)$, using the bulk density of AOT $\left(1.1 \mathrm{~g} \mathrm{~cm}^{-3}\right)$ for the organic layer is likely to lead to an overestimation of the number of AOT molecules residing on the surface. Indeed, theoretical calculations predicted that a free AOT molecule can exist in seven confirmations with an effective density ranging from 0.5 to $1.0 \mathrm{~g}$ $\mathrm{cm}^{-3} \cdot{ }^{60}$ Neutron reflectivity measurements on AOT residing at the air-water interface showed that the lower limit for the area of an AOT head is $0.78 \mathrm{~nm}^{2}{ }^{61}$ Treating AOT as a cylinder and using $1.3 \mathrm{~nm}$ as the chain length would then result in a density of $0.74 \mathrm{~g} \mathrm{~cm}^{-3}$. As a compromise, we have adopted a value of $\rho_{\text {AOT }}=0.89 \mathrm{~g} \mathrm{~cm}^{-3}$ for the effective density of the AOT outer shell.

Table 4 shows the results for the $17 \mathrm{~nm}$ AOT/ $\mathrm{NaCl}$ particles with solution weight fractions of AOT ranging from 5 to $75 \mathrm{wt}$ $\%$. The AOT surface density and coverage were calculated as follows $\left(N_{\mathrm{AOT}}\right.$ is the number of AOT molecules in the particle; $N_{\mathrm{a}}$ is the Avogrado number; $\mathrm{MW}_{\mathrm{AOT}}$ is the molecular weight of AOT).

$$
\begin{gathered}
S_{\mathrm{AOT}}=\frac{N_{\mathrm{AOT}}}{\pi d_{\mathrm{NaCl}}^{2}}=\frac{\rho_{\mathrm{AOT}} N_{a}\left(d_{\mathrm{particle}}^{3}-d_{\mathrm{NaCl}}^{3}\right)}{6 \mathrm{MW}_{\mathrm{AOT}} d_{\mathrm{NaCl}}^{2}} \\
\Theta_{\mathrm{AOT}}=\frac{S_{\mathrm{AOT}}}{S_{\mathrm{NaCl}}}
\end{gathered}
$$

According to these calculations, the coverage exceeds a monolayer only after the weight fraction of AOT reaches a rather substantial level (>50 wt \%). The $5 \mathrm{wt} \%$ and $25 \mathrm{wt} \%$ AOT/ $\mathrm{NaCl} 17 \mathrm{~nm}$ particles have anticipated $\Theta_{\text {АОт }}$ values of 0.1 and 0.4 , respectively, leaving plenty of exposed $\mathrm{NaCl}$ sites for water vapor to interact with. The experimentally determined hygroscopic growth curves (Figure 5) are qualitatively consistent with the picture of a well-exposed $\mathrm{NaCl}$ surface sparingly covered with patches of AOT as a sharp deliquescence transition is observed followed by a substantial postdeliquescence growth to the particle.

In contrast, the 50 wt $\%$ and 75 wt $\%$ AOT $/ \mathrm{NaCl}$ particles are predicted to have a much denser AOT overcoat, with an anticipated $\Theta_{\text {АОт }}=0.9$ and 1.9, respectively. These particles undergo deliquescence over a much broader range of RH values, likely as a result of heterogeneity in the structure of the AOT coating. AOT is likely to form aggregates at coverage levels exceeding one monolayer. The postdeliquescence growth is strongly suppressed reflecting the smaller amount of $\mathrm{NaCl}$ in these particles.

The reduction in both the GF and DRH values in $\mathrm{AOT} / \mathrm{NaCl}$ is consistent with previous studies of hygroscopicity of surfactant-enriched $\mathrm{NaCl}$ particles. ${ }^{58,62,63}$ The effect of the surfactant becomes more important as the particle size is reduced because of the larger surface energy contributions to the particle's free

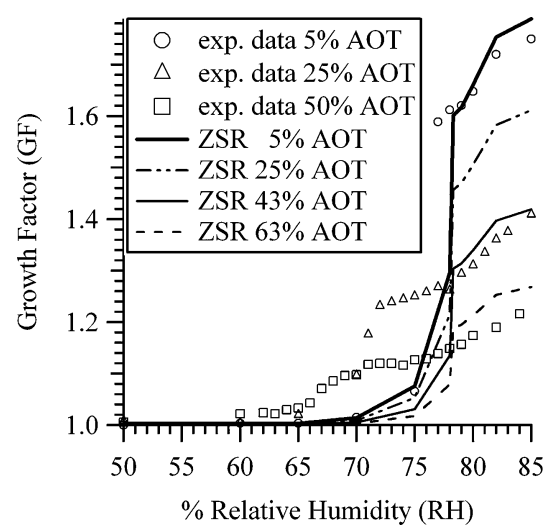

Figure 7. Predictions of the ZSR model compared to the experimental data for $17 \mathrm{~nm} \mathrm{AOT/NaCl}$ particles.

energy. For example, the 70-100 $\mathrm{nm} \mathrm{NaCl/SDS}$ particles studied by Woods et al. ${ }^{58}$ contained more than enough SDS to completely coat the surface of $\mathrm{NaCl}$. These particles deliquesced only $1 \% \mathrm{RH}$ below the deliquescence point of pure $\mathrm{NaCl}$ particles. We observed no DRH suppression in bulk AOT/NaCl mixtures (Table 3 ). In contrast, the $\mathrm{NaCl}$ nanoparticles coated with a submonolayer of AOT experienced a very significant shift in the DRH (Figure 5).

In the ZSR (Zdanovskii-Stokes-Robinson) model, the hygroscopic GF of a multicomponent system is estimated from the known GF values of its pure components and their volume fractions. ${ }^{34,36,64,65}$ The ZSR model assumes that there are no interactions among the different mixture components; therefore, the hygroscopic growth of the internally mixed particles is an appropriately weighed sum of the hygroscopic growth factors of its components. ${ }^{66}$ It also assumes an ideal mixing behavior with spherical particles having a shape factor of unity.

Application of this model to $\mathrm{AOT} / \mathrm{NaCl}$ particles predicts that GF should depend only on the volume fraction of $\mathrm{NaCl}\left(\varepsilon_{\mathrm{NaCl}}\right)$ because pure AOT particles barely absorb any water and do not deliquesce in this $\mathrm{RH}$ range $\left(\mathrm{GF}_{\mathrm{AOT}} \approx 1\right)$

$$
\begin{aligned}
\mathrm{GF}_{\text {particle }}^{3}=\varepsilon_{\mathrm{NaCl}} \mathrm{GF}_{\mathrm{NaCl}}^{3}+\varepsilon_{\mathrm{AOT}} \mathrm{GF}_{\mathrm{AOT}}^{3} \approx \\
1+\varepsilon_{\mathrm{NaCl}}\left(\mathrm{GF}_{\mathrm{NaCl}}^{3}-1\right)
\end{aligned}
$$

It is clear that the ZSR model cannot account for the downward shift in the deliquesce transition of $\mathrm{NaCl}$ induced by the AOT coating (Figure 7). According to this model, the DRH should coincide with that of the $\mathrm{NaCl}$ core; i.e., it should occur at $\geq 75 \%$ $\mathrm{RH}$. If the role of AOT were to merely reduce the available volume fraction of $\mathrm{NaCl}$ in the mixed $\mathrm{AOT} / \mathrm{NaCl}$ particles, the DRH would actually go up as the fraction of AOT increased. The experimental observations display the opposite trend. This failure of the ZSR model is a direct consequence of strong interfacial interactions between $\mathrm{NaCl}$ and AOT; they clearly cannot be viewed as independent water adsorbers. The ZSR model also performs poorly in predicting the absolute magni- 
TABLE 5: Estimated Surface Coverage for 9 nm AOT/NaCl Particles

\begin{tabular}{ccccccc}
\hline $\mathrm{wt} \% \mathrm{AOT}_{\mathrm{sol}}$ & $d_{\mathrm{NaCl}}(\mathrm{nm})$ & anticipated $\Theta_{\mathrm{AOT}}$ & $\mathrm{GF}_{\mathrm{NaCl}(\mathrm{core})}(80 \% \mathrm{RH})$ & $\mathrm{GF}_{\text {particle }}(80 \% \mathrm{RH})$ & apparent wt \% AOT & apparent $\Theta_{\mathrm{AOT}}$ \\
\hline 5.0 & 8.6 & 0.03 & 1.59 & 1.10 & 74 \\
25 & 7.4 & 0.2 & 1.58 & & 1.0 \\
50 & 6.0 & 0.5 & 1.56 & & \\
75 & 4.5 & 1.0 & 1.53 & &
\end{tabular}

tudes of the postdeliquescence GF values (Figure 7). While the model predictions for the $5 \mathrm{wt} \% \mathrm{AOT} / \mathrm{NaCl}$ particles are in fair agreement with the measured values, the model significantly overpredicts the measured GF values for the $25 \mathrm{wt} \%$ AOT/ $\mathrm{NaCl}$ particles.

An alternative explanation for the overprediction of the postdeliquescence GF values by the ZSR model is that the relative volume fractions of $\mathrm{AOT}$ and $\mathrm{NaCl}$ in the particles are not the same as those in the original solution. In fact, the ZSR model can match the postdeliquescence data quite well if we assume that the particles are somehow enhanced with AOT relative to the solution used in the electrospray generator. For example, an application of the ZSR model to a $43 \mathrm{wt} \%$ AOT/ $\mathrm{NaCl}$ mixture produces a reasonable agreement with the observed hygroscopic curves for the $25 \mathrm{wt} \% \mathrm{AOT} / \mathrm{NaCl}$ solution (Figure 7). This would imply an enhancement in AOT by nearly a factor of 2 .

To further illustrate this point, Table 4 shows the surfactant enhancements in the $17 \mathrm{~nm} \mathrm{AOT} / \mathrm{NaCl}$ particles calculated under the assumption that the ZSR model is applicable at $80 \% \mathrm{RH}$. The $\mathrm{GF}_{\mathrm{NaCl}(\mathrm{core})}$ values for this calculation are estimated by fitting the combined $\mathrm{NaCl}$ hygroscopic growth data from Table 2 to an empirical power law. The apparent volume fraction of AOT is then computed from the measured $\mathrm{GF}_{\text {particle values }}$

$$
\varepsilon_{\mathrm{AOT}}=\frac{\mathrm{GF}_{\mathrm{NaCl}(\text { core })}^{3}-\mathrm{GF}_{\text {particle }}^{3}}{\mathrm{GF}_{\mathrm{NaCl}(\mathrm{core})}^{3}-1}
$$

and converted to apparent weight fraction of AOT as well as the apparent coverage layer. This calculation has to be done iteratively because the apparent coverage layer depends on the $\mathrm{NaCl}$ core diameter, which in turn depends on AOT weight fraction according to eq 10 . This calculation is therefore repeated until convergence is achieved; the converged results are reported in Table 4 . With the exception of the $5 \mathrm{wt} \%$ and 75 wt $\%$ AOT $/ \mathrm{NaCl}$ cases, the nanoparticles appear to be enriched in AOT relative to the solutions from which they were generated. These results reflect complicated and still poorly understood dynamics of nanoparticle formation in electrospray sources.

Hygroscopic Growth of 9 nm AOT/NaCl Particles. Table 5 shows the predicted AOT surface coverage for $9 \mathrm{~nm}$ particles with AOT weight fractions ranging from $5 \mathrm{wt} \%$ to $75 \mathrm{wt} \%$. These particles are only expected to attain monolayer coverage at $75 \mathrm{wt} \%$ AOT. The $25 \mathrm{wt} \% \mathrm{AOT} / \mathrm{NaCl}$ particles should have plenty of exposed $\mathrm{NaCl}$ sites for water adsorption, and a well-defined deliquescence transition can be expected by analogy with the $17 \mathrm{~nm}$ AOT/NaCl particles. Figure 6 demonstrates that this is not the case. Although the $25 \mathrm{wt} \% \mathrm{AOT} / \mathrm{NaCl}$ particles clearly increase in size more than pure AOT particles do, there is no clear deliquescence transition. The shape of the growth curve for $9 \mathrm{~nm} 25 \mathrm{wt} \% \mathrm{AOT} / \mathrm{NaCl}$ particles (anticipated $\Theta_{\mathrm{AOT}}$ $=0.2$ ) closely resembles that for $17 \mathrm{~nm} 75 \mathrm{wt} \% \mathrm{AOT} / \mathrm{NaCl}$ particles (anticipated to be fully coated with AOT). As in the $17 \mathrm{~nm} \mathrm{AOT} / \mathrm{NaCl}$ case, a possible explanation for this behavior is surfactant enhancement relative to the bulk solution that is electrosprayed. Table 5 shows the results of the surfactant enhancement analysis similar to the one described above. In the $25 \mathrm{wt} \%$ AOT/NaCl $9 \mathrm{~nm}$ particles, calculations suggest surfactant enhancements that are 3-fold in the AOT wt \% and 5 -fold fold in the effective surface coverage.

Enhancement of surface active molecules in particles produced by electrospray sources is consistent with previous measurements. A study conducted by Tang and Smith ${ }^{67}$ revealed that smaller satellite droplets and progeny droplets generated in electrospray are in fact surfactant-enriched. Although their experimental capabilities were qualitative and unable to directly quantify the level of enhancement, they estimate off-axis droplets could be as much as an order of magnitude larger in surfactant concentration compared to on-axis droplets from ion abundance in mass spectrometry analysis. The enrichment hypothesis definitively merits further theoretical and experimental investigation.

\section{Conclusions}

We have constructed a tandem DMA apparatus and confirmed that it correctly captures the details of the hygroscopic growth of pure $\mathrm{NaCl}$ nanoparticles. The $\mathrm{NaCl}$ nanoparticles are observed to adsorb 1-4 monolayers of water below DRH. The deliquescence transitions in $\mathrm{NaCl}$ nanoparticles occur at well-defined DRH values, and the nanoparticles continue to take up water and grow above the DRH. The measured DRH values and growth factors are in quantitative agreement with previously published data. The DRH is shifted to lower values, and the growth factors are suppressed when the surfactant AOT is added to the nanoparticles. This effect is definitively particle size dependent; for example, no change in $\mathrm{DRH}$ of $\mathrm{NaCl}$ is observed for bulk AOT/NaCl mixtures. The ZSR model cannot explain the observed reduction in the $\mathrm{DRH}$ for the $\mathrm{AOT} / \mathrm{NaCl}$ particles. This observation implies that there is in fact a cooperative interaction between $\mathrm{NaCl}$, AOT, and water; the particle overall growth cannot be ascribed solely to the $\mathrm{NaCl}$ core. There is indirect evidence that the nanoparticles generated by the electrospray source are enriched in AOT compared to the electrosprayed aqueous solution.

Acknowledgment. This study was supported by the National Science Foundation through the Environmental Molecular Science Institute program, Grant CHE-0431312. Otto Dopfer is thankful to the Bavaria California Technology Center (BaCaTeC) for the travel exchange grant that supported his visit to UCI in 2007.

\section{References and Notes}

(1) Sioutas, C.; Delfino Ralph, J.; Singh, M. Environ. Health Perspect. 2005, 113, 947-955.

(2) Geiser, M.; Rothen-Rutishauser, B.; Kapp, N.; Schurch, S.; Kreyling, W.; Schulz, H.; Semmler, M.; Im Hof, V.; Heyder, J.; Gehr, P. Environ. Health Perspect. 2005, 113, 1555-1560.

(3) Oberdoerster, G.; Sharp, Z.; Atudorei, V.; Elder, A.; Gelein, R.; Kreyling, W.; Cox, C. Inhalation Toxicol. 2004, 16, 437-445.

(4) Zhu, Y.; Hinds, W. C.; Kim, S.; Shen, S.; Sioutas, C. Atmos. Environ. 2002, 36, 4323-4335. 
(5) Kulmala, M.; Vehkamaki, H.; Petaja, T.; Dal Maso, M.; Lauri, A.; Kerminen, V. M.; Birmili, W.; McMurry, P. H. J. Aerosol Sci. 2004, 35 143-176.

(6) Pierce, J. R.; Adams, P. J. Atm. Chem. Phys. 2007, 7, 1367-1379.

(7) Zhu, Y.; Hinds, W. C.; Shen, S.; Sioutas, C. Aerosol Sci. Technol. 2004, 38, 5-13.

(8) Roeselova, M.; Jungwirth, P.; Tobias, D. J.; Gerber, R. B. J. Phys. Chem. B 2003, 107, 12690-12699.

(9) Knipping, E. M.; Lakin, M. J.; Foster, K. L.; Jungwirth, P.; Tobias, D. J.; Gerber, R. B.; Dabdub, D.; Finlayson-Pitts, B. J. Science 2000, 288, 301-306.

(10) Raymond, T. M.; Pandis, S. N J. Geophys. Res. D 2002, 107, 4787 (doi: 4710.1029/2002JD002159).

(11) Martin, S. T. Chem. Rev. 2000, 100, 3403-3453.

(12) Cruz, C. N.; Pandis, S. N. Environ. Sci. Technol. 2000, 34, 43134319.

(13) Cziczo, D. J.; Abbatt, J. P. D. J. Phys. Chem. A 2000, 104, 2038 2047

(14) Braban, C. F.; Carroll, M. F.; Styler, S. A.; Abbatt, J. P. D. J. Phys. Chem. A 2003, 107, 6594-6602.

(15) Ge, Z.; Wexler, A. S.; Johnston, M. V. J. Phys. Chem. A 1998 , $102,173-180$.

(16) Liu, Y.; Yang, Z.; Desyaterik, Y.; Gassman, P. L.; Wang, H.; Laskin, A. Anal. Chem. 2008, 80, 633-642.

(17) Tang, I. N.; Munkelwitz, H. R. Atmos. Environ., Part A 1993, 27A, $467-473$.

(18) Gao, Y.; Yu, L. E.; Chen, S. B. J. Phys. Chem. A 2007, 111, 633 639

(19) Hock, C.; Strassburg, S.; Haberland, H.; von Issendorff, B.; Aguado, A.; Schmidt, M. Phys. Rev. Lett. 2008, 101, 023401/023401-023401/ 023404 .

(20) Mirabel, P.; Reiss, H.; Bowles, R. K. J. Chem. Phys. 2000, 113, $8200-8205$.

(21) Djikaev, Y. S.; Bowles, R.; Reiss, H.; Haemeri, K.; Laaksonen, A.; Vaekevae, M. J. Phys. Chem. B 2001, 105, 7708-7722.

(22) Russell, L. M.; Ming, Y. J. Chem. Phys. 2002, 116, 311-321.

(23) Bahadur, R.; Russell, L. M. Aerosol Sci. Technol. 2008, 42, 369 376.

(24) Bahadur, R.; Russell, L. M. J. Chem. Phys. 2008, 129, 094508/ 094501-094508/094510.

(25) Hameri, K.; Laaksonen, A.; Vakeva, M.; Suni, T. J. Geophys. Res. D 2001, 106, 20749-20757.

(26) Hameri, K.; Vakeva, M.; Hansson, H.-C.; Laaksonen, A. J. Geophys. Res. D 2000, 105, 22231-22242.

(27) Romakkaniemi, S.; Haemeri, K.; Vaekevae, M.; Laaksonen, A. J. Phys. Chem. A 2001, 105, 8183-8188.

(28) Biskos, G.; Russell, L. M.; Buseck, P. R.; Martin, S. T Geophys. Res. Lett. 2006, 33, L07801 (doi: 07810.01029/02005GL025199).

(29) Biskos, G.; Malinowski, A.; Russell, L.; Buseck, P.; Martin, S. Aerosol Sci. Technol. 2006, 40, 97-106.

(30) Biskos, G.; Paulsen, D.; Russell, L. M.; Buseck, P. R.; Martin, S. T Atm. Chem. Phys. 2007, 6, 4633-4642.

(31) Bahadur, R.; Russell, L. M.; Alavi, S. J. Phys. Chem. B 2007, 111, 11989-11996.

(32) Hansson, H. C.; Rood, M. J.; Koloutsou-Vakakis, S.; Hameri, K.; Orsini, D.; Wiedensohler, A. J. Atmos. Chem. 1998, 31, 321-346.

(33) Choi, M. Y.; Chan, C. K. Environ. Sci. Technol. 2002, 36, 2422 2428 .

(34) Svenningsson, B.; Rissler, J.; Swietlicki, E.; Mircea, M.; Bilde, M.; Facchini, M. C.; Decesari, S.; Fuzzi, S.; Zhou, J.; Moenster, J.; Rosenoern, T. Atmos. Chem. Phys. 2006, 6, 1937-1952.

(35) Salcedo, D. J. Phys. Chem. A 2006, 110, 12158-12165.
(36) Wise, M. E.; Surratt, J. D.; Curtis, D. B.; Shilling, J. E.; Tolbert, M. A J. Geophys. Res. D 2003, 108, 4638 (doi: 4610.1029/2003JD003775). (37) Abel, S.; Sterpone, F.; Bandyopadhyay, S.; Marchi, M. J. Phys. Chem. B 2004, 108, 19458-19466.

(38) Kotlarchyk, M.; Chen, S. H.; Huang, J. S. J. Phys. Chem. 1982, 86, 3273-3276.

(39) Zulauf, M.; Eicke, H. F. J. Phys. Chem. 1979, 83, 480-486.

(40) Fuks, N. A. Izv. Akad. Nauk SSSR, Ser. Geofiz. 1964, 579-586.

(41) Wiedensohler, A. J. Aerosol Sci. 1988, 19, 387-389.

(42) Fuks, N. A.; Sutugin, A. G. Br. J. Appl. Phys. 1963, 14, 39-42.

(43) Wise, M. E.; Martin, S. T.; Russell, L. M.; Buseck, P. R. Aerosol. Sci. Technol. 2008, 42, 281-294.

(44) Wise, M. E.; Semeniuk, T. A.; Bruintjes, R.; Martin, S. T.; Russell, L. M.; Buseck, P. R J. Geophys. Res. D 2007, 112, D10224 (doi: 10210.11029/12006JD007678).

(45) Wise, M.; Biskos, G.; Martin, S.; Russell, L.; Buseck, P. Aerosol Sci. Technol. 2005, 39, 849-856.

(46) Foster, M. C.; Ewing, G. E. J. Chem. Phys. 2000, 112, 6817-6826.

(47) Ewing, G. E. Chem. Rev. 2006, 106, 1511-1526.

(48) Ewing, G. E. J. Phys. Chem. B 2004, 108, 15953-15961.

(49) Verdaguer, A.; Sacha, G. M.; Luna, M.; Ogletree, D. F.; Salmeron, M J. Chem. Phys. 2005, 123, 124703/124701-124703/124708.

(50) Hemminger, J. C. Int. Rev. Phys. Chem. 1999, 18, 387-417.

(51) Finlayson-Pitts, B. J. Chem. Rev. 2003, 103, 4801-4822.

(52) DeCarlo, P.; Slowik, J.; Worsnop, D.; Davidovits, P.; Jimenez, J. Aerosol Sci. Technol. 2004, 38, 1185-1205.

(53) Allen, M. D.; Raabe, O. G. Aerosol Sci. Technol. 1985, 4, 269286.

(54) Verdaguer, A.; Sacha, G. M.; Bluhm, H.; Salmeron, M. Chem. Rev. 2006, 106, 1478-1510.

(55) International Critical Tables of Numerical Data of Physics, Chemistry, and Technology; Washburn, E. W., Ed.; published for National Research Council by McGraw-Hill Book Co.: New York, 1926.

(56) Garland, E. R.; Rosen, E. P.; Clarke, L. I.; Baer, T. Phys. Chem Chem. Phys. 2008, 10, 3156-3161.

(57) Chakraborty, P.; Zachariah, M. R. J. Phys. Chem. A 2008, 112, 966-972.

(58) Woods, E., III; Kim, H. S.; Wivagg, C. N.; Dotson, S. J.; Broekhuizen, K. E.; Frohardt, E. F. J. Phys. Chem. A 2007, 111, 1101311020.

(59) Tsai, D. H.; Zangmeister, R. A.; Pease, L. F., III; Tarlov, M. J.; Zachariah, M. R. Langmuir 2008, 24, 8483-8490.

(60) Derecskei, B.; Derecskei-Kovacs, A.; Schelly, Z. A. Langmuir 1999, 15, 1981-1992.

(61) Li, Z. X.; Lu, J. R.; Thomas, R. K. Langmuir 1997, 13, 36813685 .

(62) Chen, Y.-Y.; Lee, W.-M. G. J. Environ. Sci. Health 2001, A36, 229-242.

(63) Andrews, E.; Larson, S. M. Environ. Sci. Technol. 1993, 27, 857865.

(64) Dick, W. D.; Saxena, P.; McMurry, P. H. J. Geophys. Res. D 2000, $105,1471-1479$.

(65) Varutbangkul, V.; Brechtel, F. J.; Bahreini, R.; Ng, N. L.; Keywood, M. D.; Kroll, J. H.; Flagan, R. C.; Seinfeld, J. H.; Lee, A.; Goldstein, A. H. Atm. Chem. Phys. 2006, 6, 2367-2388.

(66) Stokes, R. H.; Robinson, R. A. J. Phys. Chem. 1966, 70, 21262131.

(67) Tang, K.; Smith, R. D. J. Am. Soc. Mass. Spectrom. 2001, 12, 343347.

(68) Dahneke, B. E. J. Aerosol Sci. 1973, 4, 139-145.

(69) Dahneke, B. E. J. Aerosol Sci. 1973, 4, 147-161.

(70) Dahneke, B. E. J. Aerosol Sci. 1973, 4, 163-170.

JP809869R 